\title{
geFORSETI
}

Forseti. Revista de Derecho. Edición de aniversario, Lima, DERUP, 2018, pp 144-161

\section{Incapacidad por enfermedad, uso de descansos médicos y la buena fe laboral}

\author{
María Haydée Zegarra*
}

Resumen.- La autora centra su análisis en aquellos comportamientos contradictorios en los que el trabajador podría incurrir durante el tiempo de incapacidad laboral por enfermedad. Asimismo, desarrolla pautas para determinar las actividades que son compatibles con el periodo del descanso médico y las posibles repercusiones disciplinarias en caso de que estas sean incompatibles.

Abstract.- The author focuses her analysis on those contradictory behaviors that the worker could incur during the time of incapacity for work due to illness. It also develops standards to determine which activities are compatible with the period of medical rest and the possible disciplinary repercussions if these are incompatible. 
Con cierta frecuencia, los empleadores se enfrentan a situaciones en donde el comportamiento de sus trabajadores durante el tiempo de incapacidad causado por una enfermedad, hace cuestionable su necesidad, extensión e incluso, su compatibilidad con las restricciones que ésta provoca.

Para dar contexto a esta problemática, pensemos en el caso de tres trabajadores portuarios (estibadores) que reportan lesiones físicas (desgarro tendón pectoral, lumbalgia y una lesión en el tobillo) causantes de una incapacidad para laborar que se extiende durante diez días continuos, que coincide con un viaje de estas mismas tres personas a Cancún, con pasajes comprados en forma previa a la fecha de inicio de la incapacidad; o el caso de un trabajador que sufre de una lesión lumbar causante de una incapacidad prolongada que es interrumpida para participar de un viaje de integración laboral en donde la actividad central consistía en una excursión al Huayna Picchu ${ }^{1}$.

Los casos que hemos reseñado nos servirán para reflexionar sobre la función que cumplen los descansos médicos, sobre la posibilidad de cuestionar las actividades que los trabajadores realizan durante este tiempo, y junto con ello, sobre la posibilidad de aplicar sanciones y eventualmente, el despido.

Establecidos estos puntos de estudio, desarrollaremos a continuación algunas premisas sobre las que construiremos el análisis propuesto.

\section{Incapacidad laboral por enfermedad}

Cuando un trabajador padece de una enfermedad, nuestro sistema normativo prevé que a pesar de su indisposición para laborar ${ }^{2}$, tendrá derecho a conservar sus ingresos. Detrás de esta regulación descansa la idea de que quien está impedido de trabajar a causa del deterioro de su salud tiene derecho a recuperarse sin sufrir perjuicio económico ${ }^{3}$.

1 La montaña Huayna Picchu, Wayna Pikchu en quechua, (con una altitud de 2667 msnm) forma parte de las estribaciones orientales del macizo de Salcantay, en Cusco, Perú.

2 El rol que juega la Seguridad Social permite, precisamente, que el trabajador esté amparado frente a toda una serie de infortunios que pueden ocurrir, entendiéndose que la composición misma del salario evidencia una composición mixta, una de abono inmediato y otra de beneficio diferido, y que está configurada por todas las prestaciones a las que accede el trabajador a causa de las cotizaciones que su empleador realiza en su beneficio. BAYLÓN, Gaspar. «Lección primera». En: Dieciséis lecciones sobre salarios y sus clases. Madrid, Artes Gráficas Benzal - Virtudes 7, 1971.

3 Precisamente, el artículo 15 del Decreto Supremo No 009-97-SA señala al respecto que: El subsidio por incapacidad temporal se otorga en dinero, con el objeto de resarcir las pérdidas económicas de los afiliados regulares en actividad, derivadas de la incapacidad para el trabajo ocasionada por el deterioro de su salud. Equivale al promedio diario de las remuneraciones 
Por esa razón, el empleador estará obligado a remunerar y, luego a subsidiar, las inasistencias causadas en enfermedad que se hayan justificado ${ }^{4}$ mediante la presentación de un certificado médico emitido por su médico tratante (particular o público ${ }^{5}$ ) en donde se indique el diagnóstico, tratamiento a seguir, y número de días de descanso.

El certificado médico actúa, así, como el único documento que registra el resultado de una atención médica y la necesidad de descanso físico traducido en incapacidad para laborar, por lo que su sola emisión da por cierto $^{6}$ un estado de salud o enfermedad.

En efecto, según el Código de Ética y Deontología del Colegio Médico del Perú, el certificado médico es un documento de carácter médico y legal, que da cuenta de un acto médico y de las comprobaciones obtenidas a través de aquél. ${ }^{7}$. Por tanto, los certificados no pueden

\begin{abstract}
de los últimos doce meses inmediatamente anteriores al mes en que se inicia la contingencia, multiplicado por el número de días de goce de la prestación. Si el total de los meses de afiliación es menor a doce, el promedio se determinará en función al tiempo de aportación del afiliado regular. El derecho a subsidio por cuenta del Seguro Social de Salud se adquiere a partir del vigésimo primer día de incapacidad. Durante los primeros 20 días de incapacidad, la entidad empleadora continúa obligada al pago de la remuneración o retribución. Para tal efecto, se acumulan los días de incapacidad remunerados durante cada año calendario. El subsidio se otorgará mientras dure la incapacidad del trabajador y en tanto no realice trabajo remunerado, hasta un máximo de 11 meses y 10 días consecutivos, con sujeción a los requisitos y procedimientos que señale EsSalud (énfasis nuestro).
\end{abstract}

En forma complementaria, la normativa interna emitida por la Seguridad Social (Carta Circular N 19 -GCSPE-ESSALUD-2017) ha previsto que los periodos no consecutivos de incapacidad darán derecho a un tiempo máximo de quinientos cuarenta días en el curso de treinta y seis meses.

4 Al respecto, el artículo 37 del Reglamento de la LPCL, aprobado por Decreto Supremo $\mathrm{N}^{\circ}$ 001-96-TR, señala que para que no se configure el abandono de trabajo “(...), toda ausencia al centro de trabajo, deberá ser puesta en conocimiento del empleador, exponiendo las razones que la motivaron, dentro del término del tercer día de producida, más el término de la distancia».

5 Si la atención médica es brindada por un médico privado éste le extenderá un certificado médico particular. En cambio, si la atención es brindada por un médico que pertenece a alguno de los establecimientos médicos de la red de asistencia social del Seguro Social, le extenderá un Certificado de Incapacidad Temporal para el Trabajo. En ambos casos, la inasistencia queda justificada con la presentación del certificado médico, sin que quepa exigir que el certificado médico privado sea «validado» por los médicos de la seguridad social. Este criterio fue sustentado por el Tribunal Constitucional al analizar la controversia que se discutió en el expediente 01177-2008/PA/TC del 2 de junio de 2010, en el que se concluyó que:

no cabe exigir que para la justificación de las inasistencias laborales causadas en una enfermedad los certificados médicos emitidos por médicos privados sean «validados» por un profesional de la red asistencial de la seguridad social, en tanto ésta no es una exigencia contenida en el inciso h) del artículo 25 del Texto Único Ordenado de la Ley de Productividad y Competitividad Laboral aprobada por Decreto Supremo No 003-97-TR.

6 Según la definición ofrecida por la Real Academia Española, una de las acepciones que se atribuye al término certificado es el que alude a la certificación que en él se contiene y que supone: «asegurar la verdad de un hecho».

7 La Directiva No 015-GG-ESSALUD-2014 (aplicable al procedimiento de reembolso de subsidios) define al certificado médico (CM) en los siguientes términos:

Documento que expiden los médicos después de una prestación y a solicitud del paciente. Pretende informar de los diagnósticos, tratamiento y periodo de descanso físico necesario. El Cer- 
pronunciarse sobre un acto no realizado o que exprese información falsa, inexacta o tendenciosa. Cualquier conducta en contrario podrá ser calificada como infractora del artículo $431^{8}$ del Código Penal y merecer una pena privativa de libertad de hasta tres años, más una inhabilitación para el ejercicio de la profesión de hasta dos años.

Pese a la presunción de veracidad que la ley otorga a los certificados médicos, nos interesa centrar el análisis en aquellas situaciones en donde el comportamiento de los trabajadores adquiere una dimensión que genera espacio para cuestionar que se requiera de un periodo de descanso real por padecer una enfermedad o que determinado comportamiento sea compatible con las restricciones que la enfermedad causa y que, de no ser respetadas, podrían provocar su agravamiento o retrasar la mejoría, extendiéndose -por acción directa del trabajador- el periodo de suspensión de labores.

En este punto, resulta necesario destacar que debido a la inexistencia de un procedimiento o instancia que permita a los empleadores solicitar la «revisión» de los diagnósticos y prescripciones contenidos en los certificados médicos ${ }^{9}$, el análisis que realizaremos en este trabajo estará centrado en el comportamiento de quienes hacen uso de estos certificados, sin ocuparnos de la forma o circunstancias bajo las que éstos se han expedido.

Con ese propósito, revisaremos a continuación la función que cumplen los periodos de incapacidad, y cómo las prescripciones médicas relativas a una enfermedad condicionan la conducta de quien la padece.

\section{Descansos médicos y conductas «compatibles»}

Como lo adelantamos, el descanso médico es el tiempo prescrito para que el paciente logre una recuperación física y mental que le permita

tificado Médico no suele hacer constancia de las limitaciones que la enfermedad genera en el cumplimiento de las actividades laborales.

8 El artículo 431 del Código Penal establece que: «El médico, que maliciosamente, expide un certificado falso respecto a la existencia o no existencia, presente o pasada, de enfermedades físicas o mentales, será reprimido con pena privativa de la libertad no mayor de tres años e inhabilitación de una a dos años (...)».

9 En teoría, quien tome conocimiento de alguna irregularidad en la emisión de un certificado médico podrá comunicar este hecho al Colegio Médico del Perú o a la Jefatura de Personal del Seguro Social de Salud -EsSalud-, para que se realicen las investigaciones correspondientes. No obstante, dado que estas instituciones no han desarrollado formalmente un mecanismo para recibir denuncias, será necesario enviar una comunicación con la descripción de los hechos en los que se sustente la irregularidad y los documentos que la acreditan, de modo que se evalúe la pertinencia de realizar una investigación. En este espacio, no existirá posibilidad de participar en las indagaciones que se realicen, ni en la decisión a la que se dé lugar. 
retornar a su actividad habitual. Durante este periodo, el trabajador está liberado de la obligación de laborar (es decir, incapacitado para laborar), con derecho a recibir remuneración y un subsidio a cargo de la Seguridad Social, que se solventa con las cotizaciones que realizan los empleadores por sus trabajadores en actividad.

Por esa razón, nuestra legislación prohíbe ${ }^{10}$ que quienes estén en capacidad de laborar accedan a un subsidio, de modo que si algún trabajador labora durante el tiempo de incapacidad, no podrá reclamarlo. Si no fuera así, se quebraría la premisa central sobre la que se ha construido esta protección social: brindar ayuda económica a quien no puede laborar por causa de una enfermedad de carácter temporal ${ }^{11}$.

Hasta aquí, está claro que quien padece de una enfermedad que requiere de un tiempo de descanso para recuperarse queda liberado de laborar hasta que consiga su mejoría (alta médica). No obstante, el espacio sobre el que surgen los cuestionamientos que anticipamos, es el que gira en torno a las actividades que realizan los trabajadores durante el tiempo de la incapacidad temporal para laborar.

De hecho, hay quienes defienden la tesis por la que los trabajadores serían libres de decidir la forma como cumplen su descanso médico en tanto esta libertad le es reconocida por la Constitución Política del Estado en tanto ésta señala que: «nadie está obligado a hacer lo que la ley no manda, ni impedido de hacer lo que ella no prohíbe». Desde esta postura, si algún trabajador decidiera realizar un viaje de

10 Al respecto, el artículo 15 del Reglamento de la Ley de Modernización de la Seguridad Social señala que:

El subsidio por incapacidad temporal se otorga en dinero, con el objeto de resarcir las pérdidas económicas de los afiliados regulares en actividad, derivadas de la incapacidad para el trabajo ocasionada por el deterioro de su salud. Equivale al promedio diario de las remuneraciones de los últimos doce meses inmediatamente anteriores al mes en que se inicia la contingencia, multiplicado por el número de días de goce de la prestación. Si el total de los meses de afiliación es menor a doce, el promedio se determinará en función al tiempo de aportación del afiliado regular. El derecho a subsidio por cuenta del Seguro Social de Salud se adquiere a partir de vigésimo primer día de incapacidad. Durante los primeros 20 días de incapacidad, la entidad empleadora continúa obligada al pago de la remuneración o retribución. Para tal efecto, se acumulan los días de incapacidad remunerados durante cada año calendario. El subsidio se otorgará mientras dure la incapacidad del trabajador y en tanto no realice trabajo remunerado, hasta un máximo de 11 meses y 10 días consecutivos, con sujeción a los requisitos y procedimientos que señale Essalud (énfasis nuestro).

11 En este mismo sentido se ha pronunciado la Sala de lo Social de Sevilla del Tribunal Superior de Andalucía en la sentencia emitida el día 18 de junio de 2014 (Sentencia N ${ }^{\circ}$ 1704/2014), en cuyo segundo considerando (segundo párrafo) señaló que:

(...) si el trabajador está impedido para consumar la prestación laboral a que contractualmente viene obligado, tiene vedado cualquier otro tipo de quehacer, sea en interés ajeno o propio, sobretodo si se tiene en cuenta que su forzada inactividad es compensada económicamente por la empresa y por la Seguridad Social a las que perjudica (...).

Consultado en: http://www.poderjudicial.es/search/doAction?action=contentpdf\&databasematch $=$ AN\&reference $=7161912 \&$ links $=$ simulaci $\%$ F3n $\% 20$ enfermedad\&optimi$\mathrm{ze}=20140916 \&$ publicinterface $=$ true 
vacaciones durante el tiempo de su incapacidad laboral, no cabrían cuestionamientos en tanto se trataría de una conducta no prohibida. Para quienes defienden esta tesis, hacerlo, vulneraría el principio de tipicidad y el derecho a la intimidad.

Contra esta posición, la tesis que proponemos parte de la consideración de que el empleador está legitimado para tomar decisiones basadas en el comportamiento de sus trabajadores durante el tiempo de su incapacidad laboral, aún y cuando se trate de eventos que ocurran fuera del centro laboral y en espacios no vinculados propiamente a su actividad laboral. Hacemos esta afirmación, desde la lógica de que si el trabajador se libera de laborar porque aduce necesitar de un tiempo de descanso para la recuperación de su salud, y activa así el sistema de protección social -obligando a su empleador, además, a reemplazarlo-, resulta legítimo que el empleador pueda tomar acción cuando exista evidencia de que ese tiempo no está cumpliendo esa finalidad.

Entonces, al reconocer en el empleador esta facultad, sobre la que volveremos luego, la interrogante se sitúa ahora en definir qué actividades tienen permitidas los trabajadores durante el tiempo de su incapacidad.

Frente a la inexistencia de una regulación específica que nos dé una repuesta, consideramos clave recordar que si los descansos médicos tienen como función permitir la recuperación de la salud, y ésa es la causa liberatoria de la obligación de prestar el servicio laboral comprometido en el contrato de trabajo, este tiempo sólo podría coincidir con actividades «compatibles» con las restricciones que la propia enfermedad origina.

Para dar contenido a esta propuesta y ayudados por la definición que la Real Academia Española ha desarrollado sobre dicho término debemos empezar señalando que serán «compatibles» con el uso de un descanso médico todas aquellas conductas que puedan «funcionar o coexistir» con la situación médica que lo originó.

Será útil, también, determinar si el descanso médico era de alcance «absoluto o relativo». Lo primero significará que el paciente tendría que cumplir el descanso sujetándose a una estricta inmovilización y postración, mientras que en el segundo supuesto, podrá desarrollar diferentes movimientos que no perjudique su recuperación.

Las pautas que proponemos nos ayudarán a identificar qué conductas son «compatibles» con un periodo de incapacidad por enfermedad y cuáles no. Naturalmente, no será posible encontrar una fórmula 
genérica que anticipe respuestas, pues la «compatibilidad» de una determinada conducta con la enfermedad que causa la incapacidad exigirá un análisis individualizado en el que se evaluará el tipo de enfermedad, ocupación laboral, circunstancias particulares de la persona, entre otros factores.

La complejidad que nos plantea este ejercicio valorativo, y la falta de desarrollo jurisprudencial local nos invita a revisar la experiencia de otras jurisdicciones. Así, nos interesa compartir el análisis realizado por la Sala de lo Social de Sevilla del Tribunal Superior de Justicia de Andalucía de España, en la Sentencia N No 1704/2014 del 18 de junio de $2014^{12}$, en donde se revisó la conducta de un trabajador que padecía de un trastorno depresivo, y que durante su descanso médico entrenó a un equipo de fútbol infantil.

En esa oportunidad, la Sala concluyó que tratándose de una actividad «no laboral» sino «lúdica» (de juego), no cabía calificarla como perturbadora de la recuperación del trabajador. Se concluyó, también, que esta actividad no evidenciaba que el trabajador se encontrase en condiciones para laborar, en tanto los tiempos que comprometió fueron breves.

Sirviéndonos de esta reflexión, podemos plantear una primera e importante conclusión: las conductas que ocurran durante el tiempo de incapacidad laboral tendrán que valorarse a partir de las restricciones causadas por la enfermedad que la origina. Si estas conductas no importan el ejercicio de una actividad productiva (que desdiga la necesidad del descanso) o no comprometen la recuperación o la retrasan, habrá que concluir que se trata de actividades "compatibles» con la enfermedad que originó el descanso ${ }^{13}$.

12 En el cuarto párrafo del segundo fundamento de derecho, la Sala señaló que:

Partiendo de esta doctrina jurisprudencial, esta Sala concluye, al igual que la juzgadora de instancia, que la conducta no reviste la gravedad suficiente para ser merecedora de la sanción por despido. De los hechos declarados probados se deduce que el actor, antes de causar baja por incapacidad temporal el 4 de enero de 2012 por trastorno depresivo, mantenía con la empresa un conflicto laboral sobre los salarios que le venían siendo satisfechos, lo que motivó que el 18 de enero de 2012 iniciara las acciones en reclamación de cantidad con la presentación de papeleta de conciliación ante el CMAC. La actividad que se imputa es la de entrenar a un equipo infantil de futbol de Espartinas (viviendo en Camas, utilizando para su desplazamiento un vehículo propio) los días 17, 19 y 24 de enero de 2012, de 18 a 19:30 horas, dirigiéndolos el 20 en un partido. Esos datos no son suficientes para concluir que la realización de esa actividad, no laboral sino lúdica, sea susceptible de perturbar la curación del trabajador o para evidenciar la aptitud laboral de éste, pues no es lo mismo practicar una actividad lúdica durante un breve lapso temporal algunos días, que someterse a una jornada laboral completa como dependiente, máxime cuando se concluye que había una situación de conflicto entre empleador y empresario por las condiciones laborales aplicadas. Y ya dijimos más arriba que el hecho de la medicación prescrita pueda influir en la conducción, no significa que necesariamente haya de hacerlo y, menos aún, que el ejercicio de esa actividad pueda perjudicar la curación del trabajador.

13 Para abundar, nos interesa referirnos a la Sentencia del Tribunal Superior de Canarias N ${ }^{\circ}$ 1058/2015 del 6 de julio de 2015, la misma que resolvió una controversia en la que se cues- 
Hecha esta afirmación, parece quedar en evidencia que por oposición a aquellas conductas compatibles con el descanso, podemos identificar cuáles no lo son. Este universo estará integrado, entonces, por aquellas conductas que contradicen la necesidad del trabajador de hacer uso de un periodo de descanso que lo libere de la obligación de laborar, y, junto a ello, por aquellas conductas que resultan contraindicadas para la recuperación de la enfermedad que causó la incapacidad.

\section{Conductas «no compatibles»: «contradictorias» y «contraindicadas»}

La definición de «compatibilidad» propuesta, nos sirve para integrar todas aquellas situaciones en donde la conducta del trabajador durante su incapacidad: o niega la necesidad del descanso al evidenciar su aptitud para laborar o más bien, delata la ejecución de actividades contraindicadas por la enfermedad misma, agravándola o perjudicando su recuperación.

Examinemos ahora cada uno de estos supuestos y revisemos luego sus repercusiones en el ámbito laboral.

\section{a. Las conductas «contradictorias»}

Como adelantamos, esta categoría compromete todas aquellas situaciones en donde el comportamiento de quienes justifican su incapacidad para laborar en una enfermedad, desdice la necesidad del descanso y revela, más bien, su aptitud para laborar.

Como se puede anticipar, la dificultad de enfrentar este tipo situaciones radica en que si el trabajador se reporta incapacitado para laborar y lo hace premunido de un certificado médico que se presume válido, resultará muy complejo contradecir lo que el médico diagnosticó y prescribió, salvo que a pesar de lo que está allí indicado la conducta cuestionada y las circunstancias que la rodean -sobretodo- sean lo suficientemente reveladoras de la existencia de aptitud laboral.

tionó la conducta de un trabajador que causó su incapacidad en un trastorno depresivo, asistiendo durante ese tiempo a presentaciones musicales con un grupo de aficionados al que pertenecía y donde tocó el bajo, instrumento que habitualmente practicaba. Para el Tribunal, estas actividades «lúdicas» que no le reportaron ingresos y que pudieron involucrar el consumo de pequeñas dosis de alcohol permitieron, precisamente, aliviar el trastorno depresivo que había sido generado por el trabajo.

Consultado en: http://www.poderjudicial.es/search/contenidos.action?action=contentpdf\&databasematch $=$ AN\&reference $=7504907 \&$ links $=\% 221058 \% 2$ F2015\%22\&optimi$z e=20151028 \&$ publicinterface $=$ true 
Para dimensionar la complejidad de lo que planteamos, volvamos a revisar el caso de los estibadores que propusimos al inicio de esta nota e incorporemos algunos datos adicionales que surgieron durante el desarrollo de los procesos laborales (en vía ordinaria y en virtud de los que pretendían su reposición), en los que se revisó su comportamiento ${ }^{14}$.

Para evitar generalizaciones, y no obstante fueron tres los trabajadores implicados, ocupémonos del caso de quien presentó una desgarro en el tendón pectoral mayor, y cuya declaración en el proceso oral junto a las demás pruebas permitieron establecer que: i) las actividades que realizó durante el viaje significaron un esfuerzo físico incompatible su lesión porque exigía el traslado de equipaje y desplazamiento aéreo durante varias horas, ii) afirmó haber comprado el pasaje aéreo luego de iniciado el descanso médico (porque no se condicionaba su movilidad), aunque la compañía aérea informó que el pasaje aéreo se compró con más de dos meses de anticipación a la fecha en que se realizó el viaje; y iii) que en una oportunidad previa una de las inasistencias que se justificó en una enfermedad coincidió, también, con un viaje fuera del país.

La sumatoria de todos estos hechos condujo a la Sala Laboral a desestimar la pretensión de reposición, pues no obstante se alegó que no cabía aplicar un despido «bajo la sospecha» de que la enfermedad se había inventado, se concluyó que:

(...) el demandante ha incurrido en una falta grave al distorsionar el concepto de un descanso médico, pues el hecho de viajar en esta condición (padecer dolor a nivel de la región pectoral derecho por sobre esfuerzo físico) le implica un esfuerzo físico causándole no solo un perjuicio económico a la demandada, sino también poner en riesgo su recuperación, pues éste es el fin de un descanso médico. Sin embargo, en cuanto al extremo en el cual el A quo señala que la lesión no era de la magnitud que la representó, ello sería un error del juez, pero no invalida su decisión porque como ya se ha señalado, el demandante utilizó el periodo de descanso médico que implica necesariamente reposar a fin de no afectar el padecimiento del actor dada su lesión y por el contrario se fue a un viaje de placer al exterior del país, en consecuencia no se ha vulnerado el principio de presunción de inocencia al que se hace referencia.

Como puede notarse, para calificar de «incompatible» el viaje a Cancún con las restricciones médicas causadas por la enfermedad la Sala

14 Más información sobre esta controversia puede encontrarse en el portal web del Poder Judicial: Expediente N00627-2014-0-0701-JR-LA-02.

Consultado en: https://cej.pj.gob.pe/cej/forms/busquedaform.html 
no necesitó cuestionar el certificado médico ni el diagnóstico contenido en él. No obstante, y aunque la Sala no encontró evidencia suficiente para negar la ineptitud que el trabajador adujo padecer, resulta claro que programar un viaje de placer que coincidió con una posterior lesión muscular (diagnosticada en una atención ambulatoria), y con la enfermedad de los otros dos compañeros de trabajo que compraron pasajes en la misma fecha (antes de su enfermedad), y con el mismo itinerario, sólo puede explicarse en el hecho de que el viaje se planificó con anticipación y la lesión se simuló para permitir que ese viaje se produzca en la fecha que estuvo programado.

A similar conclusión han arribado otras jurisdicciones como la española, al enfrentar situaciones de la misma envergadura. Así, nos interesa compartir las reflexiones y conclusiones de la Sala Social del Tribunal Superior de Justicia de Andalucía en el pronunciamiento que emitió el 29 de febrero de $2012^{15}$ al resolver una controversia en donde se revisó el caso de una trabajadora que luego de que se le denegara una solicitud de vacaciones, reportó su incapacidad para laborar causada en un diagnóstico que requería de la ingesta de ansiolíticos y antidepresivos, tiempo durante el que asistió a una celebración local (Romería) caracterizada por actividades festivas en donde ingirió alcohol. El Tribunal concluyó que el tiempo de descanso que se le prescribió para recuperarse de su enfermedad requería de

(...) reposo, orden y tranquilidad, circunstancias que no concurren en este tipo de Romerías, cuando además duran varios días, sumado el hecho de haber consumido alcohol teniendo prescritos antidepresivos y ansiolíticos (...). Lo probable y no olvidemos que en eso consiste la verdad procesal, es que hubo premeditación por parte de la actora en su actuar (...) (énfasis nuestro)».

Podemos concluir, entonces, que aunque sea muy poco probable que existan pruebas que permita contradecir en forma directa e irrefutable la supuesta falta de aptitud de quien se ha liberado de su obligación de laborar acusando el padecimiento de una enfermedad, será la prueba indiciaria que se obtenga al contrastar las restricciones médicas con las exigencias propias de la actividad laboral y las de actividades o conductas desarrolladas durante el periodo de incapacidad laboral, lo que permitirá resolver esta limitación. Este examen tendrá que ser casuístico con énfasis en el tipo de actividad comprometida (lúdica

15 Tribunal Superior de Justicia de Andalucía. Recurso No 1274/2011. Sentencia Nº 773/12 de la Sala de lo Social de Sevilla: 29 de febrero de 2012.

Consultado en: http://www.poderjudicial.es/search/doAction?action=contentpdf\&databasematch $=$ AN\&reference $=6357281 \&$ links $=\% 22773 \% 2$ F2012 $\% 22 \&$ optimize $=20120509 \&$ pu blicinterface $=$ true 
o retribuida), duración, frecuencia, exigencia física, gravedad de las dolencias, etc. Estas características resultarán centrales para establecer si las actividades realizadas durante la incapacidad permiten concluir que no hubo falta de aptitud causada en una enfermedad, sino, más bien, simulación.

\section{b. Las conductas «contraindicadas»}

Nos corresponde ahora revisar las conductas a las que hemos agrupado bajo la denominación de «contraindicadas» y en las que están comprendidas aquellas que perjudiquen o pongan en riesgo la recuperación del trabajador durante el tiempo de la incapacidad.

Precisamente, ciñéndonos a la definición propuesta, merecerán la calificación de «contraindicadas» todas aquellas conductas que sean peligrosas, perjudiciales, desaconsejadas o prohibidas ${ }^{16}$ con respecto a una determinada enfermedad. Nuevamente, para descubrir qué tipo de actividades merecen esta calificación se exigirá un análisis individualizado en el que se examine la enfermedad, la actividad laboral habitual, y las exigencias de la actividad ejecutada. Así, si volvemos sobre el segundo de los casos que propusimos al inicio resulta bastante claro que un recorrido de ascenso a la montaña Huayna Picchu no puede estar aconsejado para quien ha debido guardar reposo para superar una «lumbalgia prolongada» pues compromete largas horas de caminata y mucha exigencia física, en tanto implica ascender y descender de pie vía una trocha angosta durante casi seis horas.

Para profundizar en este tipo de conductas, resulta interesante comentar el pronunciamiento emitido por el Tribunal Superior de Justicia de Cataluña el 17 de abril de $2015^{17}$, en una controversia en la que un trabajador que basó su incapacidad en una enfermedad asociada a la lumbalgia, realizó diversas sesiones de spinning (ciclismo de interiores), actividad que el Tribunal calificó como incompatible con la enfermedad en razón del desgaste físico, sobreesfuerzo muscular y posiciones forzadas que esta actividad exigía.

Con base en este pronunciamiento podemos concluir, además, que merecerán esta calificación aquellas conductas que «potencialmente»

16 Todas estas acepciones corresponden a la definición del término «contraindicado» conforme al Diccionario de la Real Academia Española.

17 Tribunal Superior de Justicia de Cataluña. Recurso N 929/2015. Sentencia N² 2656/2015 de la Sala de lo Social del Tribunal Superior de Justicia de Cataluña: 17 de abril de 2015. Consultado en: http://www.poderjudicial.es/search/contenidos.action?action=contentpdf\&databasematch $=$ AN\&reference $=7411297 \&$ links $=\% 222656 \% 2 F 2015 \% 22 \&$ optimize $=20$ 150619\&publicinterface $=$ true 
sean capaces de perjudicar o retrasar la recuperación de la enfermedad que causó la incapacidad, sin que sea necesaria su ocurrencia.

Parece quedar claro, entonces, que los comportamientos que resultan contraindicados para una enfermedad, requerirán, también, de un examen casuístico en donde se revisen las circunstancias y características de cada situación. Precisamente, será este análisis fino y exhaustivo el que permitirá inferir si la actividad que se ejecutó es compatible con la enfermedad, reveladora de simulación o, quizás, contraindicada.

Establecidas estas categorías, resulta necesario anticipar que no obstante los criterios que hemos propuesto para diferenciar las conductas «simuladas» de aquellas de donde sólo sea posible deducir el riesgo de agravamiento o retraso en la mejoría, son sumamente útiles, lo cierto es que si no existieran datos objetivos, suficientes y comprobables que develen el trasfondo de lo ocurrido, bastará con volver sobre un concepto de alcance más general basado en la compatibilidad de la conducta con el diagnóstico (y las restricciones que éste causa) para cuestionar -y rechazar- las actuaciones que ocurran durante la incapacidad, sin necesidad de concluir en uno u otro sentido.

\section{Repercusiones disciplinarias}

Sin duda, la existencia de conductas que se develen como "incompatibles» con la enfermedad que causa la incapacidad para laborar nos ubica frente a la necesidad de evaluar la pertinencia de una medida disciplinaria, bajo la consideración de que aunque la incapacidad exonera al trabajador del deber de trabajar, no causa la extinción de la relación laboral y por tanto, se mantienen vigentes los deberes centrales que éste asume y que están basados en la buena fe como principio ordenador y clave en nuestro sistema normativo. Negar la posibilidad que el empresario pueda actuar en este espacio, permitiría la validación de comportamientos que actúan contra los deberes de honradez y lealtad que el trabajador asume al comprometer su actividad laboral, y sobretodo, contra la función social que cumple la «incapacidad por enfermedad» como institución jurídica reservada para la recuperación de una salud deteriorada.

Entonces, más allá de que estos comportamientos se produzcan fuera del ámbito laboral, porque es el trabajador quien se sustrae de aquél alegando una causa médica, será necesario reconocer al empleador la posibilidad de actuar sobre este ámbito para asegurar el correcto uso de las herramientas de protección social que nuestra normativa 
ha desarrollado, máxime si se tiene en cuenta que el empleador tiene una carga económica (ya sea de subvención directa de los veinte primeros días de incapacidad, o la obligación contributiva general frente al sistema de seguridad social).

Desde esta óptica, y si partimos de la premisa de que quien emplea el periodo de incapacidad para actividades que no son compatibles con su recuperación actuará en contraposición a los intereses del acreedor de su fuerza de trabajo, su empleador, habría que concluir que toda conducta que caiga en esta situación representará una trasgresión a los compromisos laborales que asumió. No sólo porque la esencia misma de la incapacidad supone que ésta se reserve para un fin terapéutico, sino porque debe hacerlo de la mejor forma posible para conseguir su más pronta recuperación y reintegrarse a su actividad laboral.

Establecida esta premisa, lo siguiente que queda por definir pasa por entender cuál es la gravedad de esta transgresión, qué tipo de sanción le corresponde y si respecto de ella opera algún criterio de graduación $^{18}$. En nuestra opinión, la ejecución de cualquier conducta que sea «incompatible» con la recuperación misma reviste de una gravedad tal que amerita la más severa sanción como lo es el despido, resultando irrelevante a estos efectos si ésta genera o no perjuicio, ni tampoco si existe intencionalidad o culpa. Hacemos esta afirmación, porque cuando se actúa contra los condicionamientos de la enfermedad se compromete una fibra muy sensible de las relaciones de trabajo como lo es la «buena fe contractual».

Básicamente, porque es la «buena fe contractual» la que actúa como limitante al ejercicio de los derechos y obligaciones de las partes, de forma que éstas no se ejecuten de una manera abusiva que lesione los intereses de la otra, sino más bien, que sirva para guiar la ejecución de las prestaciones bajo las reglas de honradez, lealtad, y confianza mutua. Este principio pone énfasis, entonces, en la necesidad de que las partes de la relación laboral, al deberse prestaciones recíprocas, actúen con rectitud de ánimo e integridad en el obrar ${ }^{19}$; sin actuar en forma desinteresada o negligente, ni menos aún, sacando provecho la una a la otra, o de las situaciones de privilegio en las que se encuentren.

Por esa razón, resultará especialmente importante que cuando se produzca una incapacidad por enfermedad, el trabajador se ocupe y se

\footnotetext{
18 Es decir, entender el tipo de transgresión cometida, la situación del trabajador, su posición en la empresa, el tipo de responsabilidades a su cargo, entre otras circunstancias concurrentes para establecer si la sanción a aplicar es la que «objetiva y razonablemente» corresponde.

19 Estas definiciones han sido tomadas del diccionario virtual de la Real Academia Española.
} 
comprometa decididamente en conseguir su recuperación, sin distraer su tiempo en otras actividades que puedan afectarla o, menos aún, en intentar simular una situación que no es real. Será el trabajador quien se encuentre en mejor posición para entender, discernir y elegir sobre su actuar poniendo foco en conseguir su recuperación para retomar su prestación laboral. Por tanto, si aprovecha esta posición en su beneficio, ocultando su verdadera aptitud laboral o ejecutando actividades que la ponen en riesgo o que pueden postergar su recuperación, desde un espacio que sólo se encuentra bajo su dominio, la transgresión a la buena fe no sólo salta a la vista, sino que, resulta sumamente grave. En nuestra opinión, sólo será posible relativizar la gravedad de esta trasgresión si las actividades ejecutadas, aún poniendo en duda su compatibilidad con las restricciones médicas provocadas por la enfermedad, fueran irrelevantes y/o esporádicas, de manera que resulten, no significativas en términos de intensidad y/o trascendencia.

En cualquier caso, la imputación que el empleador tendría que plantear para provocar la terminación justificada de la relación laboral ${ }^{20}$ estará centrada en la comisión de la falta grave tipificada en el inciso a) del artículo 25 de la Ley de Productividad y Competitividad Laboral, aprobada por Decreto Supremo No 003-97-TR (en adelante, LPCL), la cual expresamente señala que constituye falta grave: «el incumplimiento de las obligaciones de trabajo que supone el quebrantamiento de la buena fe laboral».

Podrá señalarse que al no existir una norma que delimite las acciones que los trabajadores pueden realizar durante el tiempo de su incapacidad no será posible sancionarlas en tanto, infringiéndose el principio de legalidad ${ }^{21}$, se reprimirían situaciones no relacionadas las obligaciones derivadas de la posición laboral ${ }^{22}$. En esa línea, el

20 Para nuestra legislación, la extinción de la relación laboral a causa de la comisión de una falta grave sólo puede producirse siempre que su gravedad sea de tal magnitud que haga inviable la continuidad del vínculo laboral. Ello se desprende del primer párrafo del artículo 25 de la LPCL, norma que ha fijado las causas por las que cabe proceder a un despido, el cual señala que: «falta grave es la infracción por el trabajador de los deberes esenciales que emanan del contrato, de tal índole, que haga irrazonable la subsistencia de la relación».

21 El principio de tipicidad, en materia disciplinaria, exige que la norma creadora de las infracciones y de las sanciones, deba describir clara, expresa e inequívocamente las conductas que pueden ser sancionadas.

${ }^{22}$ Al respecto, Carlos Blancas Bustamante ha señalado que: «(...) nuestro ordenamiento laboral ha optado desde sus inicios, en materia de regulación del despido, el sistema de enumeración taxativa para definir la causa grave, razón por la cual únicamente se reputa como tal aquella conducta del trabajador que se encuentre tipificada. A consecuencia de ello, si una infracción aun manifiestamente importante, intensa o grande no está expresamente señalada en la ley, siendo falta y siendo grave, no es falta grave en el estricto 
profesor Blancas Bustamante al analizar la tipificación recogida en el inciso a del artículo 25 de la LPCL ha señalado que:

nos parece, en cambio, que su alcance verdadero debe entenderse referido a la forma concreta en que el trabajador debe cumplir su prestación, o dicho de otro modo, al cumplimiento de las obligaciones específicas de la función o puesto que desempeña el trabajador, toda vez que al genérico «deber de trabajar» que impone el contrato de trabajo, debe sumarse la modalidad de la prestación, en virtud de la cual el empleador especifica las obligaciones y labores concretas que el trabajador habrá de realizar, en atención a lo convenido en el contrato, así como en la categoría y calificación, profesional ${ }^{23}$.

En el mismo sentido se pronunció la Primera Sala Transitoria de Derecho Constitucional y Social de La Corte Suprema de Justicia de La República en la Casación No 2147-2004 Lima, señalando que:

(...) el contenido estricto de esta falta reside en el incumplimiento del trabajador de las labores que tiene asignadas en la Empresa es decir las "obligaciones de trabajo" cuyo incumplimiento se tipifica como falta grave se encuentra referido al contenido propio y específico de la labor que toca ejecutar al trabajador y no lato sensu como conjunto de obligaciones que impone la relación de trabajo lo cual supondría subsumir en este supuesto todas las infracciones a las obligaciones derivadas del contrato de trabajo (énfasis agregado).

En nuestra opinión, la buena fe contractual se vulnera no sólo cuando se incumplen las obligaciones que el trabajador compromete en razón de su posición laboral específica, sino sobretodo, cuando se afecta la propia puesta a disposición, a causa de una exoneración del deber de laborar que no se atiende con corrección. Entonces, habrá tipicidad en la calificación de esta inconducta, y la incursión en este espacio de dominio del trabajador, estará justificado en la propia existencia de una conducta que se sustrae de la esfera de lo ético y lícito.

sentido jurídico que a este término se le asigna como motivo justificado de terminación de la relación contractual. (...) Como el tipo penal, la falta grave enumerada por la ley es un modelo de conducta antijurídica, que configura un marco o parámetro dentro del cual pueden comprenderse diversidad de hechos o actuaciones concretas en que puede incurrir el trabajador, los cuales, sin embargo, sólo podrán calificarse como falta grave si reúnen los elementos que definen a cada una de éstas. La eventual amplitud o generalidad en que pudieran estar formuladas algunas de las faltas graves "(...) no obsta el carácter limitativo que tales causas tienen (...)", en contraste con la remisión genérica a los incumplimientos graves, propia del derecho civil contractual, o a la ausencia de enumeración taxativa de las causas para que el trabajador extinga la relación de trabajo». BLANCAS, Carlos. El despido individual por causa justa. Lima, Jurista Editores, 2013, pp. 292-294.

23 BLANCAS, Carlos. Op. cit., pp. 292-294. 
Una postura como la que proponemos busca asegurar un comportamiento probo y honrado ${ }^{24}$ que asegure la eficacia de la prestación comprometida ${ }^{25}$ en el marco de la buena fe laboral como principio rector de las relaciones laborales ${ }^{26}$, y se ajusta a lo señalado por la Corte Suprema de Justicia en la CAS N 199-2004-PUNO en donde se señaló que:

el contrato de trabajo determina obligaciones para el empleador y trabajador, así para el primero la obligación de abonar la remuneración por servicio y para el trabajador cumplir con la prestación efectiva del servicio compatible con el carácter intuito personal de este contrato desde el punto de vista del trabajador y de la cual a su vez se deriva una serie de deberes esenciales entre ellos el de obediencia que supone respetar las norma internas y cumplir con las ordenes e indicaciones del empleador, buena fe, que supone actuar y conducirse con lealtad, probidad y corrección (énfasis nuestro) ${ }^{27}$.

Este criterio ha sido recogido también en la Casación Laboral $\mathrm{N}^{\circ}$ 9483-2012-CUSCO, en donde la Corte Suprema de Justicia, profundizando en lo anterior, ha señalado que:

Las obligaciones asumidas por las partes, con motivo del contrato de trabajo, no se limitan únicamente a las pactadas en contrato escrito, sino que las mismas derivan también, de las disposiciones normativas que la regulen. De allí que no resulte extraña la redacción del artículo 25 del Decreto Supremo No 003-97-TR, cuando prevé que constituye falta grave, aquella infracción por parte del trabajador de los deberes esenciales que emanan del contrato de trabajo, entendiéndose por tal no sólo a las obligaciones taxativamente previstas en aquel, sino a todos aquellos (...) deberes centrales del trabajador tales como el deber de poner a disposición del empleador su fuerza de trabajo en el marco de obediencia, buena fe y diligencia ${ }^{28}$.

${ }^{24}$ GAMARRA, Leopoldo. «El deber de la buena fe en el Derecho del Trabajo: las faltas graves derivadas de su incumplimiento». En: Actualidad Jurídica, Tomo 170, 2008, pp. 377-384.

25 ARCE, Elmer. Derecho Individual de Trabajo en el Perú: Desafíos y Deficiencias. Lima, Palestra, 2008, pp. 498.

26 Al respecto, Leopoldo Gamarra Vílchez ha señalado que:

(...) en los contratos y las relaciones de trabajo, las partes, se obligan a lo expresamente pactado y a las consecuencias que sean conformes a las normas del trabajo, a la buena fe y a la equidad. Esto quiere decir que la buena fe se consagra como un principio general del Derecho que puede ser entendido de maneras diferentes, más que un catálogo de buenos propósitos en las relaciones laborales, implica una obligación jurídica que protege la confianza razonable, que debe existir en el comportamiento laboral.

GAMARRA, Leopoldo. «El deber de la buena fe en el Derecho del Trabajo: las faltas graves derivadas de su incumplimiento». En: Actualidad Jurídica, Tomo 170, 2008, pp. 380

27 Corte Suprema de la República. Casación N 199-2004-PUNO de la Primera Sala Transitoria de Derecho Constitucional y Social: 17 de abril de 2006.

http://vlex.com.pe/vid/-472635990

${ }^{28}$ Corte Suprema de la República. Casación No 9483-2012-CUSCO de la Sala de Derecho Constitucional y Social: 30 de setiembre de 2013.

Consultado en: https://www.pj.gob.pe/wps/wcm/connect/619bde80427978f4a257af5fde5b89d6/9483-2012_ok.pdf?MOD=AJPERES\&CACHEID=619bde80427978f4a257af5fde5b89d6 
En lo relativo al deber de buena fe, la misma sentencia señala lo siguiente:

(...) su acepción objetiva es la que adquiere mayor relevancia para la ejecución del contrato de trabajo, al tratarse de una relación jurídica personal y de duración continuada que exige a los sujetos intervinientes (empleador y trabajador), un comportamiento adecuado para el cumplimiento de los deberes que cada uno posee. En función de este principio, se impone la observancia del adecuado esfuerzo volitivo y técnico para realizar el interés del acreedor del trabajo (empleador), así como para no lesionar derechos ajenos, pues como señala el extinto profesor Plá Rodríguez: «El contrato de trabajo no crea solo derechos y obligaciones de orden exclusivamente patrimonial, sino también personal. Crea, por otra parte, una relación estable y continuada, en la cual se exige la confianza recíproca en múltiples planos, en encontradas direcciones y sobretodo, por un periodo prolongado de tiempo. Para el debido cumplimiento de estas obligaciones y el adecuado mantenimiento de estas relaciones resulta importantísimo que ambas actúen con buena fe.

\section{Conclusiones}

La incapacidad temporal para trabajar causada en una enfermedad que se sostiene en los mecanismos de protección que brinda la seguridad social supone que el trabajador está impedido de realizar su actividad laboral; no obstante, eso no significa que durante este tiempo le esté vedada la ejecución de todo tipo de actividades. Por el contrario, podrán realizarse todas aquellas actividades que sean compatibles con las restricciones médicas causadas por la dolencia que provoca el descanso, es decir, aquellas que no perturben o retrasen la recuperación del trabajador, o no revelen la existencia de una «incapacidad simulada».

El análisis en torno a la «compatibilidad» de la conducta, entonces, se realizará en función de las restricciones médicas propias de la enfermedad, las tareas laborales habituales y aquellas comprometidas en la actividad sujeta a revisión. Sólo si de este examen se concluyera que se incurrió en una conducta incompatible con la enfermedad podrá deducirse la existencia de una transgresión laboral capaz de causar la terminación justificada de la relación laboral, salvo que, por su envergadura, la conducta cuestionada resulte irrelevante para efecto de la recuperación misma, en cuyo caso tendrá que evaluarse la pertinencia de una medida disciplinaria distinta.

Para finalizar, no quisiéramos dejar de señalar que el propósito de este trabajo no es alentar la imposición de sanciones, sino llamar la atención sobre la importancia de trabajar en la educación y sensi- 
bilización de los trabajadores, para el correcto entendimiento de la función que cumplen los descansos médicos que causan la incapacidad para laborar, de forma de construir una cultura laboral que aliente comportamientos éticos transparentes e informados. 